\title{
El patrimonio histórico como recurso didáctico en el Parque Nacional del Teide
}

\author{
Hacomar Ruiz González ${ }^{a}$, Efraín Marrero Salas ${ }^{b c}$, Juan Carlos García Ávila ${ }^{c}$, Ithaisa Abreu Hernández ${ }^{\mathrm{c}}$ \\ Matilde Arnay de la Rosa ${ }^{\text {d }}$ \\ ${ }^{a}$ Universidad de La Laguna, Facultad de Humanidades, Campus de Guajara, 38200 La Laguna, Santa Cruz de Tenerife, \\ haruizgon@gmail.com, bUniversidad de La Laguna, Facultad de Humanidades, Campus de Guajara, 38200 La Laguna, Santa Cruz \\ de Tenerife, emarreros85@gmail.com, 'Prored Soc. Coop., Isabel González “Azucena Roja”, n², 38002 Santa Cruz de Tenerife, \\ proredsc@gmail.com, 'Universidad de La Laguna, Facultad de Humanidades, Campus de Guajara 38200 La Laguna, Santa Cruz de \\ Tenerife, matarnay@ull.es
}

\begin{abstract}
Resumen
El Parque Nacional del Teide es un espacio geográfico que destaca por sus características geológicas y naturales únicas, las cuales le valieron su declaración como patrimonio mundial en 2017. No obstante se trata también de un territorio humanizado desde la etapa prehispánica, cuyas actividades dejaron su huella en el territorio, dando a la arqueología numerosas pautas para conocer cómo se articuló la ocupación guanche de la alta montaña de Tenerife.

En la actualidad el profesorado de enseñanza secundaria parte de un inconveniente destacable que es la falta de yacimientos arqueológicos visitables en la Isla de Tenerife, espacios en los que el alumnado pueda consolidar su conocimiento relativo a las culturas aborígenes canarias. Por ello con nuestro trabajo se pretende hacer un análisis del potencial didáctico para las Ciencias Sociales, y especificamente para la materia de Historia, de un espacio geográfico como es el Parque Nacional del Teide, presentando una propuesta que integre a Las Cañadas del Teide en la enseñanza de la etapa prehispánica de las Islas, teniendo en cuenta aspectos relacionados con el uso de objetos arqueológicos, visitas guiadas o actividades relacionadas con la disciplina arqueológica.
\end{abstract}

Palabras clave: educación, historia, patrimonio arqueológico, Parque Nacional del Teide, arqueología.

\begin{abstract}
Teide National Park is a geographic space that has unique geological and natural characteristics, which validated its declaration as World Heritage Site in 2017. However, human activity has been recorded since pre-hispanic times, whose actions left their mark in the territory, this has allowed archaeology to understand how "guanche" human occupation has been articulated in the high mountain contexts of Tenerife.

Nowadays, high school teachers have the inconvenient of a severe lack of visitable archaeological sites in Tenerife. Spaces in which the students can elaborate their knowlege about the aboriginal cultures of The Canaries. Therefore, in this article we intend to analyze the educative potential of this geographic space for the teaching of the Social Sciences, and especifically for History. We present an educative proposal which integrates Teide National Park in the education methods of the pre-hispanic period, specially having in mind the use of archaeological items, guided visits or other activities.
\end{abstract}

Keywords: education, history, archaeological heritage, Teide National Park, archaeology. 


\section{Introducción}

Dentro del imaginario colectivo y en la propia filosofía que inspiró la creación de los parques nacionales, la naturaleza inalterada fue considerada como la característica mas representantiva de los mismos. El Parque Nacional del Teide (Tenerife) no escapó a dicha consideración, dado que sus especiales características geológicas y naturales le valieron la declaración de Patrimonio de la Humanidad en 2007. No obstante, debe entendenderse que se trató también de un espacio geográfico humanizado desde la etapa prehispánica de la Isla hasta la actualidad.

En este sentido Las Cañadas del Teide fue un territorio caracterizado por una explotación de tipo económico entre las que destaca la extracción de sus recursos líticos, en particular obsidianas y rocas de basalto vacuolar que fueron aprovechadas por parte de los guanches y la utilización de dicho territorio para las actividades ganaderas y el aprovechamiento de los productos vegetales no forrajeros. La situación de Las Cañadas del Teide, ocupando toda la parte central de la isla de Tenerife, tuvo mucho que ver en la utilización de este territorio como espacio de encuentro y via de comunicación entre las diferentes comunidades de la Isla, sin obviar su gran valor simbólico (Tejera, 1988; Diego Cuscoy, 2015; Arnay et al., 2017b).

Sin embargo la impronta arqueológica de estas actividades presente en el Parque Nacional de Teide y el conocimiento fruto de las diversas intervenciones en los últimos años, ha pasado desapercibida para la población, algo que no ocurre con las características geológicas y naturales de Las Cañadas. La causa en cierta medida está en la ausencia en la actualidad de un centro interpretativo de los vestigios arqueológicos del Parque Nacional del Teide y la escasa inclusión de las culturas aborígenes canarias en los curriculums de la educación secundaría obligatoria.

\section{Objetivos}

El presente trabajo tiene como objetivo principal realizar una propuesta para integrar los bienes arqueológicos presentes en el Parque Nacional del Teide como recurso didáctico para las asignaturas ligadas con la historia de Canarias, buscando de esta forma por un lado, romper con el hándicap existente en la isla de Tenerife ante la inexistencia de yacimientos arqueológicos visitables desde la perspectiva educativa, que han impedido al profesorado y alumnado poder llevar a cabo este tipo de actividades fuera del aula, y por otro lado persiguiendo dar a conocer el pasado arqueológico de Tenerife y en particular el de Las Cañadas del Teide, haciendo hincapié en la importancia que tiene preservar estos vestigios y por tanto concienciar al alumnado respecto a la protección y conservación del patrimonio histórico.

Teniendo como escenario la red de senderos e itinerarios del Parque Nacional, se persique por tanto proponer el desarrollo de actividades que persiguen concienciar y hacer participe a la sociedad en la protección, conservación y promoción de este tipo de itinerarios, objetivos ya apuntados en la Carta de Itinerarios Culturales de ICOMOS (ratificada por la $16^{\text {a }}$ Asamblea General ICOMOS, Québec (Canada), 4 de octubre 2008), y siguiendo la estela del trabajo y propuesta que ha desarrollado el área de Patrimonio Histórico del Cabildo Insular de Tenerife para que el Camino Real de Chasna (el cual pasa por Las Cañadas del Teide) forme parte de la Red de Itinerarios Culturales Europeos.

\section{Desarrollo del tema}

Sorprende observar la escasa utilización que se ha hecho del patrimonio histórico del Parque Nacional del Teide aunque la idea de insertar los bienes culturales y patrimoniales de Las Cañadas en la didáctica no es nueva. Un antecedente interesante fue desarrollado en la década de los 90 por Ana $\mathrm{M}^{\mathrm{a}}$ García Pérez, catedrática de Geografía e Historia. Esta profesora elaboró una serie de cuadernos de campo que bajo el título "Un tramo del antiguo camino de Chasna, a su paso por las Cañadas del Teide" buscaban acercar al alumnado de secundaria no solo al pasado histórico de la alta montaña de Tenerife, sino que también indagaba en cuestiones relacionadas con la flora, fauna y las características geológicas del Parque, llevándose a la práctica en dicha década con visitas del alumnado del Instituto de CanariasCabrera Pinto. A ello debe sumarse que el propio Parque Nacional ha desarrollado en los últimos años actividades 
ligadas con la educación ambiental, dirigidas a los centros docentes de la Isla, y que mediante charlas y las posteriores visitas guiadas al parque alcanzan la cifra de 13.000 estudiantes que hacen uso de este servicio al año.

Todo ello nos llevo a entender el gran potencial didáctico que tienen Las Cañadas del Teide, no solo para las materias relativas a la Historia, sino también para la enseñanza de otras disciplinas. En definitiva, es el Parque Nacional del Teide un marco singular, en el que apreciar la idea de continuidad y constante evolución de un territorio a lo largo de su historia a través del análisis de las huellas que dichas actividades dejaron. En lo referente al periodo de ocupación aborigen de la alta montaña de Tenerife, destaca la presencia de yacimientos en superficie como cabañas, refugios o abrigos, ligados generalmente a la presencia estacional de los pastores guanches en este territorio y por tanto a la actividad trashumante de los mismos. A esta actividad económica debe unirse el aprovechamiento de los recursos líticos de Las Cañadas, ya sea tanto de obsidiana como de rocas basálticas, que, si bien inicialmente la investigación arqueológica desarrollada en el Parque creyó que era una actividad complementaria al pastoreo, se ha puesto de manifiesto en los últimos años que dichas actividades distan mucho de ser meramente complementarias, como muestra la existencia de importantes canteras-taller, de obsidiana y de roca vacuolar para la fabricación de molinos de mano rotatorios (Diego Cuscoy, 2015; Alberto et al., 2007; Arnay et al., 2017b).

A estas labores de tipo económico deben unirse cuestiones ligadas con el mundo simbólico aborigen, que se manifiestan este territorio los espacios funerarios, pero tambien en el carácter sacro del Teide, montaña sagrada o axis mundi, siendo Las Cañadas un marco clave para entender la mitología guanche y las cuestiones ligadas a su religiosisad. Tras la conquista de la Isla en 1496, Las Cañadas adquieren otro significado que explica las transformaciones sociales derivadas de la integración de Tenerife en la Corona de Castilla. Un ejemplo de estas transformaciones lo tenemos en el fenómeno de los alzados, que muestran una perivencia de la cultura guanche, ligada a la clandestinidad, en las zonas de alta montaña de Tenerife y que pervive hasta bien entrado el siglo XVI (Arnay et al., 2017a; Pou et al., 2015).

Todos estos elementos inciden en la importancia que tiene el marco geográfico de Las Cañadas del Teide como lienzo en el que se han dibujado las diferentes etapas de la historia de Tenerife, y señalan el interés que tiene la alta montaña de Tenerife, no solo como territorio de estudio para comprender mejor la ocupación aborigen de la misma, sino como espacio cuyos recursos arqueológicos pueden ser aprovechados desde la perspectiva didáctica. Partimos de la premisa de que si queremos afianzar el conocimiento de la historia del archipiélago Canario, y en particular su etapa prehispánica en el alumnado de la Islas, mas allá de ampliar las horas lectivas destinadas a los temas relacionados con la historia de Canarias (actualmente las culturas aborígenes canarias pueden ser abordadas desde tres asignaturas) debe desarrollarse un aprendizaje significativo. Es aquí donde entran los bienes patrimoniales y la arqueología, la cual se convierte en una herramienta que si bien no aparece en los currículos de historia, sí aborda transversalmente dichas materias y tienen un gran potencial didáctico, tanto en la adquisición de contenidos como en el desarrollo de competencias (Egea y Arias, 2013; 2015; Castillo, 2017; Rivero et al., 2018)

\section{Metodología}

La metodología desarrollada y estructurada en varias fases busca responder al objetivo principal que no es otro que plantear posibles herramientas y fórmulas para integrar los yacimientos arqueológicos de Las Cañadas del Teide y su bienes patrimoniales como recurso para la didáctica de la historia.

Para ello en primer lugar se ha realizado una lectura intensiva de los currículos de las materias de la Educación Secundaria Obligatoria de Canarias para conocer qué aspectos de los mismos (Criterios de Evaluación, contenidos y estándares de aprendizaje) y de qué manera podían ser abordados, teniendo como hilo conductor los bienes patrimoniales del Parque Nacional del Teide. Partimos además de trabajos previos en los que se ha evaluado la visión que de los aborígenes canarios se tiene por parte del alumnado en la actualidad, y cuyos resultados muestran una imagen alejada de la que emana del conocimiento científico actual (Bencomo, 2018).

De la mano de diferentes proyectos de investigación se ha hecho un esfuerzo considerable en los últimos años no solo en la catalogación de los recursos arqueológicos y etnográficos existentes en el Parque Nacional del Teide, sino también en desarrollar un plan de difusión. Fruto de este trabajo y de algunas de las actividades llevadas acabo tales como la 
formación a los guías del Parque Nacional del Teide, el desarrollo de rutas temáticas o la realización de exposiciones itinerantes, y a su vez de los resultados obtenidos, se han seleccionado tanto los maletines didácticos como la red de senderos del Parque Nacional del Teide como materiales para adaptar este trabajo a las necesidades del profesorado y el alumnado de la ESO en Canarias. En lo que se respecta a los itinerarios, se establecieron una serie de criterios para la elección de los senderos mas adecuados para la actividad docente, tales como la accesibilidad, la duración y el valor histórico del mismo, motivos que propiciaron la elección del sendero $\mathrm{n}^{\mathrm{o}} 32$ de Abeque como el más apto para desarrollar en él la actividad didáctica.

\section{Resultados y propuestas de inserción}

En este sentido, y tras el trabajo anteriormente citado en materia de investigación cientificia y difusión de los resultados obtenidos, se han planteado las siguientes propuestas o actividades que pudiesen ser realizables por el alumnado de Secundaria y que respondieran de manera efectiva a los criterios y contenidos marcados por los currículos emanados de la Consejería de Educación, Universidades, Cultura y Deportes del Gobierno de Canarias (Decreto 83/2016 de 4 de Julio - BOC n⿳⺈冂136, de 15 de Julio).

\subsection{Los itinerarios}

Partiendo de la red de senderos y caminos del Parque Nacional del Teide, y conociendo los bienes patrimoniales asociados a los mismos, sería interesante valorar el potencial de los mismos para insertarlos en la docencia. Es evidente que la dimensión espacial juega un papel significativo en el proceso de enseñanza y aprendizaje, dado que permite al alumnado comprender que las actividades humanas dejan huella con mayor o menor envergadura en el espacio en el que se desarrollan (Hernández Cardona, 2005). Es por ello que en la enseñanza de la geografía (y, obviamente la historia) las salidas y trabajos de campo son fundamentales dado que permiten al alumnado interactuar tanto con el medio como con fuentes primarias, y construir su aprendizaje en un medio diferente. Sin olvidar que el desarrollo de estas salidas de campo no solo producen un cambio en la rutina diaria del aula, sino que son una inmejorable herramienta para que el alumnado pueda empatizar con los protagonistas de la historia y sea capaz de comprender con mayor amplitud los procesos que en dicho territorio han acaecido (Prego y Muñiz, 2006; Hernández Cardona, 2011).

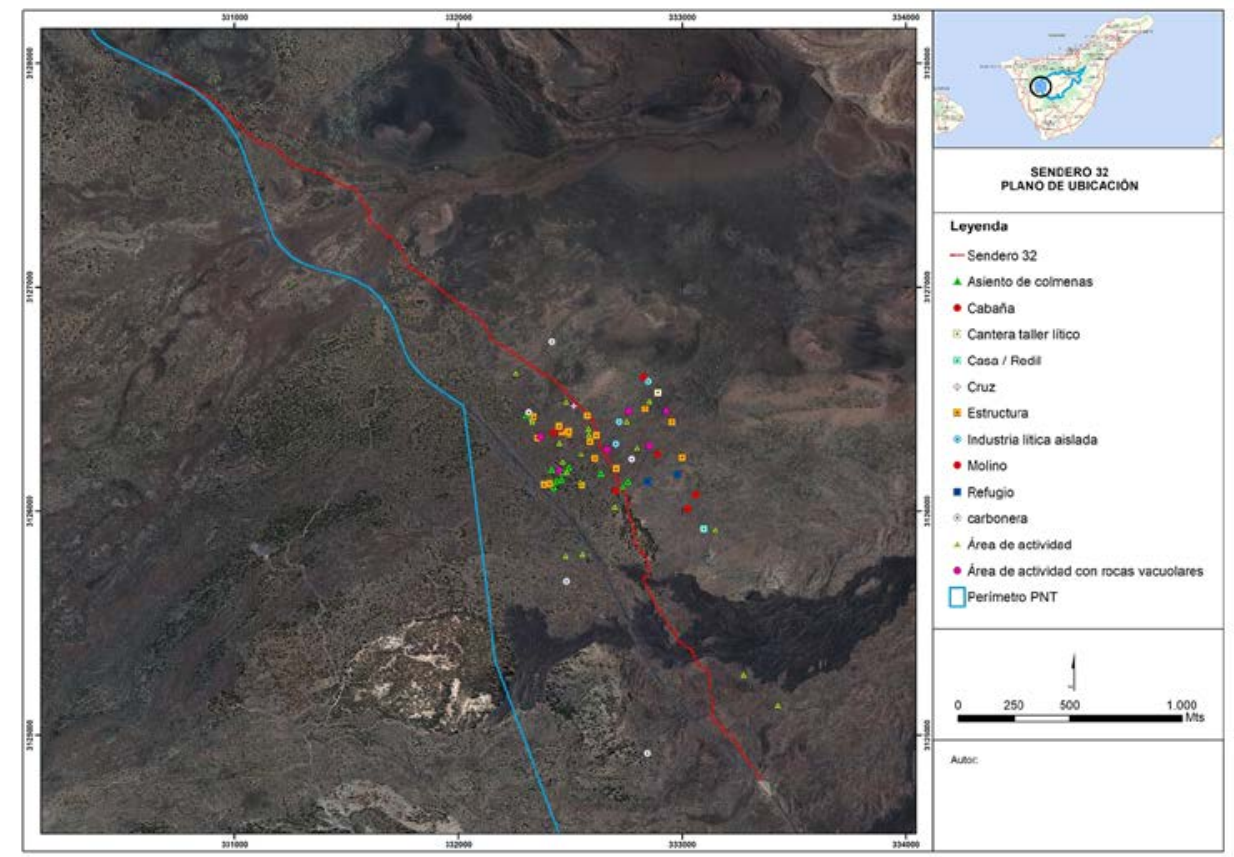

Fig. 1 Plano de distrubición de los bienes patrimoniales entorno al sendero $\mathrm{n}^{0} 32$

El Parque Nacional del Teide tiene a disposición de sus visitantes una extensa red de senderos, que pueden tener un especial interés didáctico, pero que atendiendo a criterios de accesibilidad, dificultad y extensión de los mismos hacen 
arduo el desarrollo de la actividad docente. Por el contrario, otras rutas como la $n^{\circ} 2$ de Arenas Negras, el sendero $n^{\circ} 4$ de Siete Cañadas o el sendero $\mathrm{n}^{\circ} 32$ de Abeque (Fig. 1), aúnan el interés histórico y patrimonial de la ruta con la accesibilidad y la escasa duración del recorrido de los mismos. Esta última ruta ( $\mathrm{n}^{\circ} 32$ ) es además de especial interés histórico dado que al conectarlo con los senderos $\mathrm{n}^{\circ} 13$ y $\mathrm{n}^{\circ} 9$ acaba discurriendo por uno de los antiguos caminos usados históricamente por la población de la isla (Arnay et al., 2017a).

A partir de este sendero $\mathrm{n}^{\mathrm{o}} 32$, y contemplando el valor arqueológico y patrimonial de dicho itinerario, hemos desarrollado una propuesta de cuaderno de campo que aune los bienes tanto arqueológicos como etnográficos adscritos a dicha ruta y que nos permiten ver la evolución histórica de la ocupación de la alta montaña de Tenerife. El visitante accederá por tanto a espacios concretos como el yacimiento arqueológico de Cruz de Tea, compuesto por diversas estructuras de piedra relacionadas con la captación y trabajo de la industria lítica por parte de los aborígenes canarios, o a diversos yacimientos etnográficos ligados a la explotación del territorio posteriormente a la conquista castellana, como es el caso de las colmeneras o las carboneras.

La idea con la que se elaboran estos recursos didácticos es que tanto el alumnado como el profesorado pueda, a través de una serie de ítems, guiar su aprendizaje. Estos ítems, a modo de paradas concretas en puntos de especial interés histórico, se articulan a partir de los diversos tipos de ocupación de Las Cañadas del Teide en su historia, teniendo cabida cuestiones ligadas al mundo aborigen, al uso de los caminos tradicionales o al mundo simbólico. En este caso las diferentes paradas vienen acompañadas de una serie de cuestiones y recursos que buscan por un lado guiar la actividad y por otra completar la información y hacer mas provechoso el itinerario realizado. Para ello se ha recurrido a la incorporación de textos históricos y litererarios, y a recursos como fotografías o mapas antiguos, que permitirían en este caso al alumnado poder completar información y responder a la diversas cuestiones o reflexiones que se les plantee.

Tabla 1. Estructura del cuaderno de campo para el sendero $n^{0} 32$ Abeque

\begin{tabular}{ccc}
\hline Paradas & Recursos & Bienes patrimoniales \\
\hline $\begin{array}{c}\text { 1. Aspectos generales sobre los } \\
\text { aborígenes canarios }\end{array}$ & Textos & \\
2.El camino & Mapa antiguo de Tenerife & Sendero n'32 Abeque \\
F. Arqueologia en el Teide & Cerámica e industria lítica aborigen & Yacimiento arqueológico de "Cruz de \\
4. El mundo simbólico & Planimetría del yacimiento & Tea" \\
& Textos & Montaña de Cruz de Tea y Pico Viejo \\
& & Cruceiro y altar cristiano asociado al \\
& & sendero n⿳32 \\
5.Etnografía en Las Cañadas & & Carboneras y colmeneras \\
\hline
\end{tabular}

\subsection{Las Cañadas al aula: los objetos arqueológicos}

Las fuentes primarias son los medios que dotan al historiador para conocer con mayor profundidad el pasado, pero también son herramientas con un gran potencial didáctico. Los objetos arqueológicos se convierten en imprescindibles en la enseñanza de la historia dado que permiten al alumnado relacionarse con las fuentes primarias y romper con la monotonía del libro de texto, provocando un cambio de dinámica que le permite reflexionar sobre estos objetos y plantearse cuestiones diversas ligadas a la funcionalidad de los mismos, cronología o el material en el que están confeccionados (Hernández Cardona, 2005; Prats y Santacana, 2011).

Por ello, y gracias a la colaboración del Parque Nacional del Teide, se han desarrollado diversos maletines didácticos con réplicas de objetos arqueológicos destinados al alumnado de secundaria y con el fin de que se pueda interactuar con ellos. Por lo general centran su contenido en utensilios propios de la vida cotidiana aborigen, ya sean punzones, 
recipientes cerámicos o instrumental lítico. Con este tipo de materiales se abren por tanto alternativas diferentes a la hora de desarrollar la clase, y favorecen la labor del docente, dado que vienen acompañados de dossieres (Fig. 2) con una explicación práctica de los utensilios y materiales que contienen. De este forma el profesorado, que no tiene porqué ser un experto en el tema, puede prepararse las sesiones previamente y contestar a aquellas dudas que surjan durante el desarrollo de la misma.

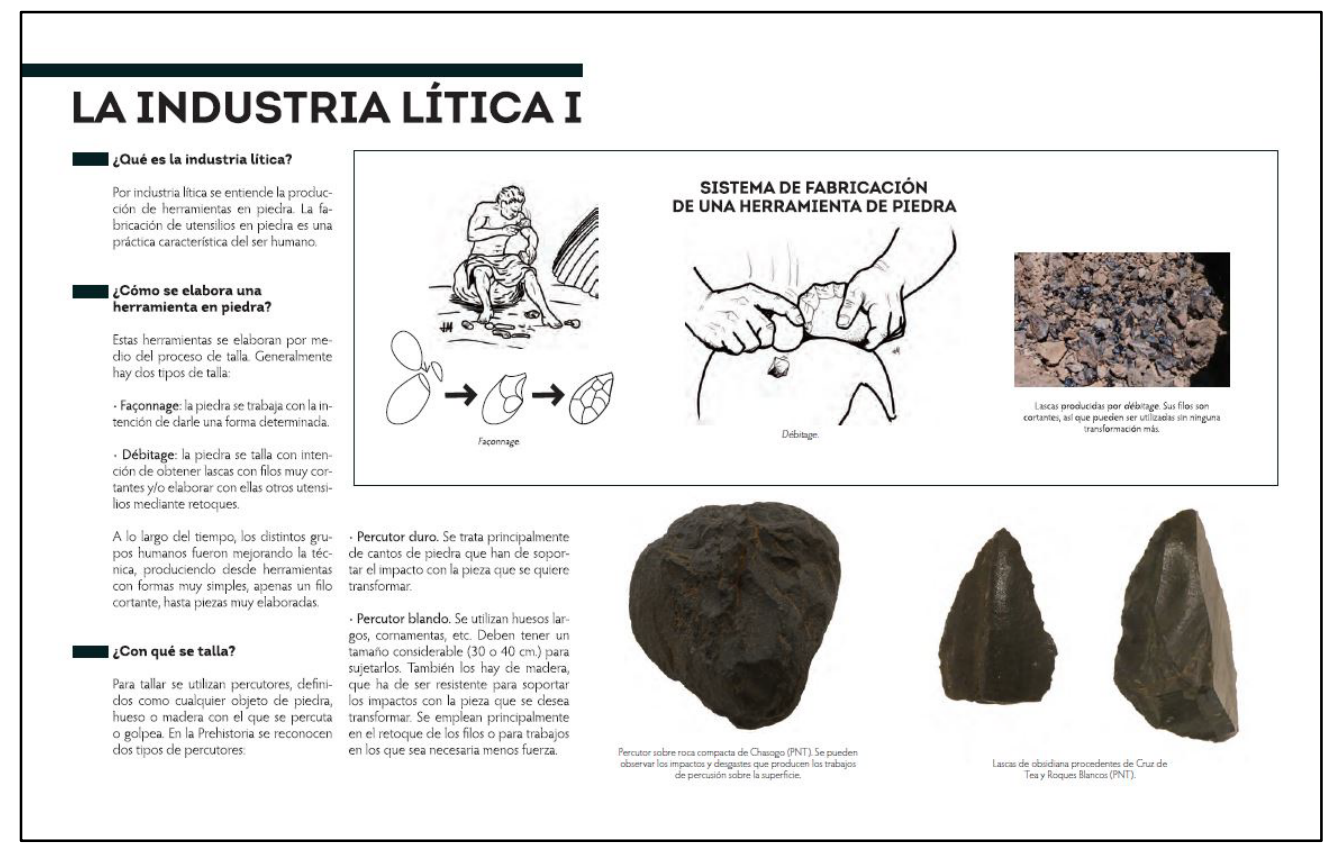

Fig. 1 Imagen de uno de los dossiers de los materiales didácticos

\subsection{Visitas a exposiciones itinerantes}

Como ya mencionamos anteriormente, el patrimonio arqueológico y etnográfico existente en el Parque Nacional del Teide, si bien es de gran valor científico para poder comprender el desarrollo de la presencia humana en este espacio, ha pasado desapercibido para el visitante. Factores que explican este fenómeno es tanto la escasa monumentalidad de los restos arqueológicos localizados en Las Cañadas del Teide como la inaccesibilidad de algunos de estos vestigios, sin obviar el peso que ha tenido la difusión de sus valores estrictamente naturales.

Algunas de las medidas desarrolladas ${ }^{1}$ en estos años ha sido la puesta en marcha de una página web (www.patrimonioarqueologicodelteide.com), el diseño de los materiales educativos anteriormente expuestos y la realización de diversas exposiciones temporales. En este último caso cabe mencionar la exposición itinerante "Caminos heredados. Estudios sobre el patrimonio arqueológico del Parque Nacional del Teide", la cual ha sido albergada en diversos puntos de las islas de Tenerife y el Hierro, en la que no solo se han presentado los resultados obtenidos, sino que se han habilitado diversos recursos también muy interesantes desde la perspectiva didáctica como son el caso de impresiones 3D o modelados fotogramétricos de algunos objetos arqueológicos donde, a través de una pantalla táctil el alumnado puede interactuar.

Si bien este tipo de exposiciones han estado dirigidas al público en general, su visita por parte de los centros educativos de la isla debe fomentarse, a pesar de las dificultades inherentes a la misma al tratase de exposiciones temporales y con las limitaciones espaciales y de horario impuestas por los espacios en lo que se albergan.

\footnotetext{
${ }^{1}$ Los trabajos en materia de difusión, al igual que los trabajos relacionados con la investigación de Las Cañadas se enmarcan en dos proyectos de investigación: Guanches y Europeos en Las Cañadas del Teide. Ocupación, producción y comunicación (HAR2015-686323-P) y Estudio y conservación de bienes arqueológicos en el contexto de las canteras -taller de molinos guanches en Las Cañadas del Teide. Una Propuesta de sostenibilidad ambiental y patromonial, apoyado por la Fundación CajaCanarias y la Obra Social La Caixa (2017REC21).
} 


\section{Conclusiones}

El Parque Nacional del Teide fue declarado Patrimonio Mundial atendiendo a sus valores estrictamente naturales, si bien nunca se ha obviado que estamos ante un paisaje humanizado, con una importancia económica y social reseñable en la historia de la Isla de Tenerife que abarca desde el periodo aborigen hasta nuestros días. Partiendo de esta premisa, hemos considerado necesario destacar dicho valor histórico en el campo de la didáctica, a pesar de la dificultad de acceso a los yacimientos arqueológicos y el escaso conocimiento que tiene el público en general sobre el patrimonio histórico y etnográfico del Parque Nacional del Teide.

Es evidente que la falta de espacios arqueológicos visitables en la Isla de Tenerife obliga a los docentes a buscar otros lugares en lo que poder llevar a cabo experiencias o itinerarios que afiancen el conocimiento adquirido en las aulas por parte del alumnado. Es por ello que entendíamos interesante presentar no solo el potencial didáctico del patrimonio histórico de Las Cañadas, sino mostrar algunos de los recursos disponibles para la elaboración de una situación de aprendizaje que aborde los criterios relacionados con el mundo aborigen de Canarias con Las Cañadas del Teide como marco. El objetivo de esta propuesta es acercar la disciplina arqueológica y el conocimiento del pasado aborigen al alumnado, sin perder un fin claro de la labor docente que es la de concienciarlos sobre la importancia de conservar y estudiar nuestro patrimonio, partiendo de una de las premisas del Plan de Educación y Patrimonio (2015) del Ministerio de Educación, Cultura y Deporte, que es la importancia de la educación patrimonial como vía para la preservación del mismo, y no solo atendiendo al ámbito formal, sino tambien a la educación en los ámbitos no formal e informal.

Una de las conclusiones mas importantes a las que hemos llegado es relativa a las limitaciones que estas propuestas de inserción tienen. La primera, obvia, es la conectividad de los centros educativos con el Parque Nacional del Teide que dificulta enormemente la realización de una actividad en el mismo que se ajuste al horario lectivo del centro educativo. A esto se le suma la falta de un centro de interpretación de los bienes patrimoniales del Teide, que si bien en parte compensan las exposiciones itinerantes anteriormente citadas, el carácter de las mismas hace difícil que estas puedan ser aprovechadas por los docentes. Partimos además de una situación en la que, aunque algunos de los recursos anteriormente expuestos han sido fomentados y financiados por parte de las instituciones, como es el caso de los maletines didácticos, estos son completamente desconocidos por el profesorado de secundaria y por tanto las propuestas de inserción anteriormente planteadas no han sido puestas en práctica en los centros de secundaria de Tenerife, si bien sí en la Universidad de La Laguna.

Esto refleja la necesidad de fomentar el dialogo y cooperación entre el profesorado y las instituciones, y abordar de manera conjunta estrategias que tengan como fin concienciar y sensibilizar el alumnado con el patrimonio. En el caso concreto de la isla de Tenerife debe aspirar no solo a formar ciudadanos activos en la protección y conservación del patrimonio mediante la educación, sino también a trabajar en la senda de otros territorios que han desarrollado programas educativos dentro del ámbito formal y no formal de especial interés, como son el del Centro de Arte Rupestre Tito Bustillo, el programa Arqueologia somos Todos (Grupo de Investigación Sísifo, Universidad de Córdoba) o la neocueva "Ekainberri” (Fontal y Martínez, 2016; Ibáñez et al., 2017).

\section{Referencias}

Alberto Barroso, V., Hernández Gómez, C. M., Barro Rois, A., Borges Domínguez, E., Prieto Rodríguez, D., Dorta Barreiro N., y García Ávila, J. C. (2007). Arqueología en el sur de Tenerife. El mito de los paraderos pastoriles. Tabona, (15), 91-114.

Arnay de la Rosa, M., García Ávila, J. C., Marrero Salas, E., Criado Hernández, C., y González Reimers, E. (2017a). Footpaths marked by changes in geological clasts as indicators of mobility in Tenerife, Canary Islands. Environmental archaeology, 24 (3), 285-293.

Arnay de la Rosa, M., González Reimers, E., Pou Hernández, S., Marrero Salas, E., y García Avila, J. C. (2017b). Prehispanic (Guanches) mummies and natrium salts in burial caves of Las Cañadas del Teide (Tenerife). Anthropologischer Anzeiger, 74 (2), 144-153.

Arnay de la Rosa, M., Marrero Salas, E., Abreu Hernández, I., y García Ávila, J. C. (2018). Caminos Heredados. Estudios sobre el patrimonio arqueológico del Parque Nacional del Teide. Catálogo de exposición. Gobierno de Canarias. Dirección General de Patrimonio Cultural. 
Ballart, J. (2002). El patrimonio histórico y arqueológico: valor y uso. Barcelona: Ariel.

Baucells Mesa, S., García Ávila J. C., y Arnay de la Rosa, M. (2006). Arqueología histórica de Alta Montaña en Tenerife. Las huellas de la subsistencia. Coloquio de Historia Canario.Americana, 14, 522-548.

Bencomo Viala, M. (2018). La imagen de los antiguos canarios entre el alumnado: sobre resultados del aprendizaje. Trabajo Final de Máster. Universidad de La Laguna. San Cristóbal de La Laguna.

Carrión Gutiez, A. (Coord.). (2015). Plan Nacional de Educación y Patrimonio. Madrid: Ministerio de Educación, Cultura y Deporte. Subdirección General de Documentación y Publicaciones.

Castillo Lozano, J. (2017). La importancia de la arqueología en las aulas: la recreación de una excavación arqueológica como actividad innovadora en la educación del alumnado de la E.S.O. Otarq, 2, 411-428.

Diego Cuscoy, L. (2015). Los Guanches: vida y cultura del primitivo habitante de Tenerife. La Laguna: Instituto de Estudios Canarios.

Egea Vivancos, A., y Arias Ferrer, L. (2013). I.E.S. Arqueológico. La arqueología como recurso para trabajar las competencias básicas en la educación secundaria. Revista clío, 39.

Egea Vivancos, A., y Arias Ferrer, L. (2015). La arqueología llega a las aulas. Objetos y otras fuentes primarias para la enseñanza de la historia. En G. Sole (Ed.), Educação patrimonial: Contributos para a construção de una consciencia patrimonial, 153-169. Portugal, Centro de investigação y Instituto de Educação Universidade de Minho.

Fontal Merillas, O., y Martínez Rodríguez, M. (2016). La educación patrimonial como praxis pedagógica para la enseñanza de la arqueología. En M. Delgado Torres, D. Vaquerizo Gil y A. Ruiz Osuna (Eds.), Rescate: del registro estratigráfico a la sociedad del conocimiento: el patrimonio arqueológico como agente de desarrollo sostenible, 141-153. Córdoba, Universidad de Córdoba.

Hernández Cardona, F. X. (2005). Didáctica de las ciencias sociales, geografia e historia. Barcelona: Graó.

Ibañez Extxeberría, A., Kortabitarte, A., Molero, M.B., y Luna, U. (2017). Aprendizaje de Prehistoria y Arqueologia en una neocueva: relación entre competencia, percepción de aprendizaje y satisfacción. Estudios pedagógicos, 43(2), 137-146.

Prats, J. (2001). Valorar el patrimonio histórico desde la educación: factores para una mejor utilización de los bienes patrimoniales. Didáctica de las Ciencias sociales, 15, 157-171. Universidad de Zaragoza.

Prats, J., y Santacana, J. (2011). Los restos arqueológicos, los monumentos y los museos como fuentes del pasado. En J. Prats (Coord.), Geografia e Historia. Investigación, innovación y buenas prácticas, 39-68. Barcelona, España: Graó.

Prego Axpe, A., y Muñiz Martínez, R. (2006). La didáctica del museo y del yacimiento arqueológico. MARQ, Arqueología y museos,(1), 169-181.

Pou Hernández, S., Arnay de la Rosa, M., García Ávila, J. C., Marrero Salas, E., y González Reimers, E. (2015). Arqueología funeraria en la Alta Montaña de Tenerife (Islas Canarias). En Arqueología de Transição: o Mundo Funerário. Actas do II Congresso Internacional sobre Arqueología de Transição (pp. 307-317). Universidad de Evora.

Rivero García, M. P., Fontal Merillas, O., Martínez Rodríguez, M., y García Ceballos, S. (2018). La educación patrimonial y el patrimonio arqueológico para la enseñanza de la Historia: el caso de Bilbilis. Ensayos: Revista de la Facultad de Educación de Albacete, 33(1), 23-27. 